Physical aspects of biological systems

Biophysik: Ein Lehrbuch. Edited by W. Hoppe, W. Lohmann, H. Markl and H. Ziegler. Pp. 720. (Springer: Berlin, Heidelberg and New York, 1977.) DM98; \$43.20.

A TEXTBOOK which describes biophysical approaches and physical aspects of biological systems would fill a gap, because most existing books deal with methods preferentially. The present book written by 54 authors, mostly from Germany, takes an interesting step in this direction.

The strongest part of the book is contained in the many chapters on biophysical aspects of various systems written by many well known workers in the field. These contributions range from enzymes as catalysts (Huber), membranes (Fisher, Stoeckenius, Sackmann and Frömter) and receptors (Thurm, Kaissling, Menzel, Snyder and Stieve), through photosynthesis (Renger) and muscle-contraction (Mannherz. Holmes) to complex systems such as information transduction in nerve systems (Creutzfeldt), orientation in flight (Reichardt), biomechanics of flight (Nachtigall) and transport of water in plants (Ziegler)-to mention only a few examples. Most of these contributions are very informative reviews of 10-20 pages written for undergraduate students or scientists who wish to broaden the scope of their knowledge. They provide a convenient source of information for many facets of biophysics and cannot be found in such a concise way in other textbooks. Three purely biological or biochemical chapters on the living cell (Schnepf), chemical structure of biological macromolecules (Tschesche) and biological function of nucleic acids (Zillig) are useful, but the information can be found also in other texts.

Chapters dealing with more general aspects of biophysics such as intra- and intermolecular interactions (Hofacker and Ladik), energy transfer (Dörr and Kuhn), kybernetics (Marko) or evolution (Kuhn and Schuster) do not add up to a complete picture. This part of the book naturally suffers more than the other part from the way it was written, namely by many rather specialised authors. For example, the chapter on interactions, written by two theoretical chemists, emphasises the quantum mechanical approach for the theoretical calculation of hydrogen bonds and charge transfer complexes but leaves out hydrophobic interactions and other important contributions.
Chapters on energetics and kinetics contain a basic sketch of general thermodynamics and fundamental kinetics without much emphasis on biological problems. Sections on thermodynamics of macromolecules in solution, multiple equilibria, polyelectrolytes, and so on, would have been valuable. Surprisingly the dynamic aspect of the function of biological macromolecules are not treated, methods (Rüppel) is included.

A chapter on physical methods for the investigation of biological macromolecules is of heterogeneous quality. The description of methods for solutions cannot compete with good introalthough a good section on fast kinetic

ductionary texts such as Van Holde's Biophysical Chemistry.

Lecturers and students who are engaged in courses of biophysics would welcome a text on general biophysics. The present book cannot be recommended as a basic text but it may serve as a supplementary book for advanced reading. A difficulty for a worldwide use of the book arises from the fact that it is written in German. This is an anachronism for a book of this type, but perhaps an English translation is planned.

Jürgen Engel

\section{Indignation against mercury pollution}

Mercury Contamination: A Human Tragedy. By P. A. D'Itri and F. M. D'Itri. Pp. xxii+311. (Wiley: New York, London, Sydney and Toronto, 1977.) £13.45; $\$ 22.80$.

THE aim of this book is to raise indignation against environmental pollution in general, and pollution by mercury in particular. Beyond the problem of environmental pollution, there is an historical account on the use of mercury. The story of its medicinal use, especially for the treatment of syphilis (as presented by the authors), is a warning to scientists to analyse all information critically and not to substitute possibilities for facts. Unfortunately, the authors do not draw the same conclusion.

There is no doubt about the environmental impact of mercury pollution in the North American lakes and rivers; there is no doubt about the unacceptably high level of methylmercury in fish caught in some of these waters; there is no doubt that methylmercury is a highly toxic accumulative poison, but these facts are not substitutes for the complete lack of controlled morbidity data for the populations of White Dog and Grassy Narrows Reserves. The lack of morbidity or mortality data, to say the least, is surprising. It is alleged that an official admitted "it was a wonder more Ojibways (of the Grassy Narrows) were not dying because some of them had blood mercury levels that exceeded those of fishermen who died at Minamata". It is also surprising that these Indians had higher blood levels than fishermen at Minamata, as, according to the authors, the highest hair level of the members of the Ojibway tribe was $40 \%$ lower than the hair level at which Japanese at Minamata began to show
Jïrgen Engel is Professor of Biophysical Chemistry at the Biozentrum of the University of Basel, Switzerland. symptoms. Another reason for surprise is that blood mercury concentrations were not estimated in the victims of the Minamata epidemic. In the same chapter there is another misquotation or uncritical quotation which states that $200 \mathrm{~g}$ fish consumed for 3 weeks raises the mercury concentration in the blood to 2 p.p.m. A $70-\mathrm{kg}$ man, however, ought to consume $10.7 \mathrm{mg}$ mercury as methylmercury per day for 3 weeks to produce 2 p.p.m. blood concentration-that is, he should eat fish containing an unbelievably high (more than 50 p.p.m.) concentration of mercury.

These and similar overstatements do not help but rather weaken the impact of the book. Mercury, according to the authors, injures at a lower dose and at an earlier time than scientific evidence indicates. As they suspect that mercury had some role in the death of Napoleon, they bring forward his death before the One Hundred Days and Waterloo to the time of his first exile on the Isle of Elba.

These criticism might seem unjustified, as in the preface the authors made it clear that "The book was not written for scientists who conduct research into mercury pollution", probably because compared with the Toronto Globe and Mail, and the Kenora Daily Miner and News, the scientists are inferior as creators and absorbers of information. First of all, "The scientific method by definition is partial and incomplete" (which is true); secondly, "local citizens instinctively grasp the problem and insist on resolution while scientists are still trying to ensure that their findings are accurate"; and thirdly, even if they are able to grasp the problem "the scientists carefully qualified statements may confuse the public."

Laszlo Magos

Laszlo Magos is a Senior Scientific Officer at the MRC Toxicology Unit, Carshalton, Surrey, UK. 